\title{
Reprodutibilidade do questionário dia típico de atividade física e alimentação
}

\author{
Reliability of a new questionnaire for the evaluation of habitual \\ physical activity and food consumption in children
}

1 Universidade Federal do Rio Grande do Norte. Departamento de Educação Física. Rio Grande do Norte, Brasil.

\section{Bolsista CAPES.}

Recebido em 15/09/08 Revisado em 13/02/09 Aprovado em 29/05/09
Abstract - The aim of this study was to determine the reliability of the Physical Activity and Food Consumption (PAFC) questionnaire in schoolchildren from a private school in Natal-RN, Brazil. A total of 101 children, 57 boys and 44 girls (mean age: 9.4 years, SD: 1.03, range: 7.3 to 11.6 ) in the second to fourth grade of elementary school were recruited. An expanded version of the PAFC questionnaire was applied at the school by a single researcher, with an average of 15 days between test and retest. The coefficient of relative agreement, intraclass correlation coefficient, Spearman's correlation coefficient, kappa index of agreement, PABAK, and Wilcoxon signed-rank test were used to determine reliability. In general, relatively consistent measures between the two questionnaire sessions were found for items related to attitude towards exercise (0.41), means of transportation used to travel to and from school (0.79), and the remaining 11 physical activities (0.69). An intraclass correlation of 0.87 as obtained for the overall physical activity index. Twentyseven of the 42 items presented moderate to good agreement (mean kappa index: 0.51). The PAFC questionnaire showed moderate to good reliability for most of its items and seems to be a suitable instrument for the evaluation of physical activity and food intake behavior in schoolchildren. Moreover, the questionnaire might be used as an alternative for the classification of more and less active individuals as well as for the identification of healthy and inadequate dietary patterns.

Key words: Motor activity; Eating behavior; Child; Reproducibility of results.

Resumo - O estudo teve como objetivo determinar o nível de reprodutibilidade do questionário Dia Típico de Atividade Física e Alimentação (PAFC) quando aplicado a escolares de Natal-RNBrasil. Participaram do estudo 101 escolares $\left(9.4 \pm 1.03\right.$, mín.7.3 e máx. 11.6 anos) das $2^{a}, 3^{a}$ e $4^{a}$ séries do ensino fundamental de uma escola da rede privada de Natal-RN, sendo 57 meninos. O instrumento foi aplicado nas salas de aula por um único avaliador, com o auxílio de uma versão ampliada, num intervalo médio de 15 dias entre teste e reteste. Para os itens relacionados à atitude da criança em relação ao exercício (0.41), tipos de deslocamento até a escola (0.79) e as 11 atividades físicas ilustradas (0.69) foram encontradas medidas relativamente consistentes entre as duas aplicações. Quanto ao índice geral de atividade física obteve-se uma correlação intraclasse de 0,87 Vinte e oito dos 42 itens da seção alimentar apresentaram concordância de moderada a boa (kappa médio: 0.51). O instrumento apresentou de moderada a boa reprodutibilidade, parecendo ser viável para o estudo dos hábitos de atividade física e alimentação de crianças mais jovens, sendo uma alternativa na classificação de indivíduos mais ativos e menos ativos, além de identificar padrões alimentares inadequados à saúde.

Palavras-chave: Atividade motora; Comportamento alimentar; Criança; Reprodutilibilidade dos resultados. 


\section{INTRODUCTION}

Studies have shown that risk factors for cardiovascular and other chronic non-communicable diseases may develop during childhood and adolescence and are associated with morbidity and mortality in adulthood $^{1-6}$. This finding demonstrates the need for primary prevention in childhood and adolescence, including dietary control and physical activity (PA) as health-promoting measures ${ }^{1-3,7,8}$. Thus, it is essential that measures of food intake and PA in population studies be accurate and reliable to permit the design of suitable interventions and the assessment of their effectiveness.

Cognitive and memory capacity are cited as two of the main limitations to developing more accurate instruments for the assessment of selfreported PA and eating behavior in children ${ }^{9,10}$. In a review, McPherson et al. ${ }^{11}$ evaluated the psychometric properties of diet-measuring methods in school-age children and pointed out the limitations of the studies as well as the lack of a standard method.

In an attempt to identify associations and a dose-response between PA and health, various techniques and instruments for assessing PA in different population groups have been described in the literature, ${ }^{9,12,13}$. In this respect, direct monitoring (accelerometers, pedometers, heart rate monitors, behavioral observation) has been recommended for children ${ }^{12,13}$. However, these methods are difficult to use in population-based studies because of their sophisticated nature and high cost.

In an attempt to provide a useful tool for epidemiological studies, Barros et al. ${ }^{14}$ developed a questionnaire to evaluate dietary habits and to estimate PA level in children ranging in age from 7 to 10 years, the Physical Activity and Food Consumption (PAFC) questionnaire. This instrument uses illustrative figures of likely daily activities of children, including commuting to school, domestic chores, sports and recreational activities, among others, permitting children to indicate the intensity of the activity according to the colored illustrations. In addition, the PAFC questionnaire permits children to indicate which food groups they habitually consume during the different meals of the day.

The objective of the present study was to determine the reliability of the PAFC questionnaire in estimating PA and habitual food intake in schoolchildren from the city of Natal, Brazil.

\section{METHODS}

The first phase of data collection was conducted in July 2005 and included schoolchildren in the first to fourth grade $(n=256)$ of a private school in Natal, Brazil. A total of 101 schoolchildren participated in the second phase conducted 15 days later. The sample consisted of $30 \%$ of the schoolchildren in the age group studied ( 57 boys and 44 girls; mean age: $9.41 \pm 1.03$ years, range: 7.3 to 11.6 years). The PAFC questionnaire was originally designed for children ranging in age from 7 to 10 years. However, since the sample was selected according to grade, children older than 10 years were included in this study.

The project was approved by the Research Ethics Committee of Universidade Federal do Rio Grande do Norte (protocol: 047/05), and the parents or legal guardians signed an informed consent form authorizing the participation of their children in the study.

\section{PAFC questionnaire}

The PAFC questionnaire refers to habitual PA and food consumption on a typical day, excluding PA and food consumed on an irregular basis, i.e., fewer than three times per week. Concurrent validation against proxy reports of parents and teachers showed a coefficient of concordance of $74 \%$ and kappa index of 0.28 for physical activity items and 42 to $92 \%$ when food PAFC's session was compared with a $24-\mathrm{h}$ recall ${ }^{14}$.

The instrument consists of two distinct sections. The first is related to PA: attitude towards exercise, commuting to school and PA performed. The second section is related to food consumption and attitudes towards the 16 food items. The child's overall PA level is determined by summing the scores of activities that the child reports to perform on most days of the week. Three different weights are attributed to classify these activities: a score of one for low-intensity activities (slow), three for moderate-intensity activities (fast), and nine for high-intensity activities (very fast). For example, a child selecting the options "slow" and "fast" for the activity "dancing" receives a score of 4 for this activity, which is then added to the scores of the remaining activities. According to the authors, this classification corresponds to the approximate metabolic cost of the different activities performed at different intensities. The maximum score possible is 147 and for a while there are no criteria to classify the subject's PA levels ${ }^{14}$. 
The food consumption section of the PAFC questionnaire provides information on items such as the choice of food groups consumed on a typical day. This section permits the qualitative analysis of food intake based on the classification of meals and snacks according to the combination of food groups with different nutrient sources, the main meals of the day, and the attitude of children towards the four different food groups ${ }^{14}$.

\section{Procedures}

The questionnaire (monochromatic version) was applied in a coordinated manner during regular class hours using an expanded (colored) version, $45 \times 65 \mathrm{~cm}$ for each page on sessions 1 and 2 (T1 and T2). Each child received a questionnaire and a colored pencil. The examiner, using vocabulary and gestures appropriate for the age group, explained the purpose of each question and the procedure to be adopted for filling out the questionnaire. To define habitual PA and food consumption, the examiner explained that the behavior must occur on most days of the week, i.e., three or more times. Furthermore, the children were asked whether they consumed other foods that were not included in the instrument and were instructed to write the name of the food on the part referring to the meal in question. The average time required to complete the instrument was 40 minutes.

\section{Statistical analysis}

A test and retest procedure was used to determine the reliability of the instrument, with a mean interval of 15 days between test (T1) and retest (T2). The data were analyzed statistically using the Excel program and a spreadsheet developed by MacKinnon ${ }^{15}$ to compute adjusted kappa indices. The data were tabulated using the EpiData software, version 3.16.

Relative agreement, Spearman's correlation coefficient, and kappa index of agreement $(\mathrm{k})$ were used to determine the degree of consistency between the information obtained (nominal and ordinal scales) at T1 and T2. Due to the asymmetry of data distribution in the contingency table, compromising the interpretation and calculation of kappa, a kappa index adjusted for prevalence and bias, called prevalence-adjusted bias-adjusted kappa (PABAK), was calculated according to the literature ${ }^{17,18}$. In addition, the intraclass correlation coefficient and Wilcoxon signed-rank test for matched pairs (numerical scales) were used to determine the consistency of PA scores. For the purpose of comparison, most analysis and data presentation procedures used in the validation study, including kappa index interpretation, were maintained in the present study ${ }^{14}$.

\section{RESULTS}

Measures of physical activity

Boys presented a significantly higher mean overall PA level than girls. The first and third quartiles are also shown as possible limits to differentiate more active from less active children (Table 1).

Table 1. Mean and first and third quartiles of overall physical activity level according to gender obtained in the first PAFC test session.

\begin{tabular}{lccc}
\hline Gender & $1^{\text {st }}$ quartile & $3^{\text {rd }}$ quartile & Mean $(S D)$ \\
\hline Boys $(n=57)$ & 47.5 & 97.0 & $73.6( \pm 32.25)$ \\
Girls $(n=44)$ & 38.0 & 67.8 & $55.0( \pm 26.76)$ \\
\hline
\end{tabular}

Taking the data from the first PAFC session, we observed that all PAs, except for "skateboarding" (48.5\%), were reported by more than $70 \%$ of the children, considering at least one intensity level.

The attitude of the children towards physical exercise was positive (like or like a lot) in almost all of them (98\%). Commuting to school was predominantly sedentary. The car and school bus appeared in $87.2 \%$ of the responses, whereas only $11.9 \%$ of the children reported commuting to school in an active manner (walking or cycling).

Analysis of the consistency of information regarding the attitude of children towards exercise and means of transportation used to travel to school showed Spearman's correlation coefficients of 0.41 and 0.79 , respectively, indicating relatively consistent measures. The reliability indices of the 11 types of PA in the PAFC questionnaire are shown in Table 2. All items related to PA presented statistically significant correlation coefficients ( $p<$ 0.05) ranging from 0.50 (dancing) to 0.86 (playing ball, soccer). However, some activities presented a wide confidence interval (dancing, walking, rope jumping). Comparison of the PA measures between T1 and T2 using the Wilcoxon signed-rank test showed that the "rope jumping" activity was significantly higher in T2 than in T1 and "domestic chores" was lower in T2 when compared to T1. Analysis of the overall PA index, corresponding to the sum of scores obtained for each type of activity, showed an intraclass correlation coefficient of 0.87 (95\% CI: 0.81-0.91). There was no significant difference between the set of data obtained in the 
Table 2. Comparison of physical activity measures between the two applications (T1 and T2) of the PAFC questionnaire ( $\mathrm{n}=101)$.

\begin{tabular}{|c|c|c|c|c|}
\hline Type of physical activity & $\frac{\mathrm{RA}}{\%}$ & \multicolumn{2}{|c|}{ Mean (SD) } & $\operatorname{ICC}(95 \% \mathrm{Cl})$ \\
\hline Dancing & 35 & $5.0(4.6)$ & $5.5(4.6)$ & $0.50(0.25-0.66)$ \\
\hline Playing with the dog & 48 & $5.0(4.8)$ & $5.5(5.1)$ & $0.75(0.62-0.83)$ \\
\hline Domestic chores & 42 & $7.6(4.8)$ & $6.7(4.5)^{*}$ & $0.68(0.53-0.79)$ \\
\hline Rope jumping & 37 & $3.7(3.9)$ & $5.6(5.3) *$ & $0.51(0.27-0.67)$ \\
\hline Climbing stairs & 38 & $5.4(4.8)$ & $5.4(4.8)$ & $0.62(0.43-0.74)$ \\
\hline Playing soccer & 49 & $6.4(5.4)$ & $6.7(5.3)$ & $0.86(0.80-0.91)$ \\
\hline Swimming & 47 & $7.2(4.7)$ & $6.9(4.8)$ & $0.79(0.69-0.86)$ \\
\hline
\end{tabular}

*Significant difference between T1 and T2 ( $<<0.05$, Wilcoxon signed-rank test). RA: relative agreement (T1=T2); SD: standard deviation; ICC: intraclass correlation coefficient; $\mathrm{Cl}$ : confidence interval.

first $(65.5 \pm 31.2)$ and second session $(66.8 \pm 32.0)$ (Wilcoxon signed-rank test).

\section{Measure of dietary habits}

Using the data obtained in the first PAFC test session as a reference, we found that a typical breakfast included foods such as yogurt, chocolate-based products, milk and derivatives, fruit, bread, eggs, and juice. These food items were reported by more than $59 \%$ of the children. For the morning snack, more than $50 \%$ of the children reported the consumption of fruit, juice, sweets, and filled cookies. For lunch, food items such as beans (96\%), rice (96\%), meat $(92.1 \%)$, juice $(86.1 \%)$, pasta $(73.3 \%)$, soft drinks (63.3\%), and legumes and vegetables (64.4\%) were reported. For the afternoon snack, the food items reported by more than $59 \%$ of the children were sweets and cookies, soft drinks, yogurt, pizza, hamburgers, and juice. For dinner, more than 53\% of the children reported to consume pasta, juice, pizza, hamburgers, soft drinks, and eggs.

Food items such as tapioca, manioc, wieners, and corn derivatives such as couscous, "pamonha" (paste made of corn and milk) and "canjica" (corn pudding) were the most frequently reported items not present in the instrument. These items are related to cultural habits, especially in June.

Agreement in food consumption of approximately $75 \%$ was observed between the first (T1) and second (T2) PAFC test session. Consumption of beans and rice in the afternoon and of fish in the morning showed the highest consistency between the two tests (>90\%), whereas consumption of dairy products in the afternoon presented the lowest consistency $(<60 \%)$.
Kappa indices showed poor agreement in three of the 42 items related to food consumption at different times of the day, weak agreement for 27 , and moderate agreement for 10 . Only the item related to yogurt consumption in the morning presented substantial agreement. However, analysis of adjusted kappa values showed an index higher than 0.41 for 28 items. These results are shown in Table 3, in addition to the relative agreement and percentage of children who reported consuming different food groups at different times of the day (morning, afternoon and evening).

Spearman's correlation coefficients for the attitude of children towards the different food groups were 0.68 for the fruit and juice group, 0.62 for artificial juices and soft drinks, 0.58 for legumes and vegetables, and 0.32 for beans and rice, indicating relatively consistent measures, except for beans and rice.

\section{DISCUSSION}

This study evaluated some of the psychometric properties (reliability) of the PAFC questionnaire, which was used to collect information about PA and dietary habits of children ranging in age from 6 to 11 years attending a school in Natal-RN, Brazil.

Although not providing an objective measure of PA such as time spent on activities or an estimate of energy expenditure for possible comparison with other studies, this instrument seems to overcome some of the limitations observed when applying questionnaires (self-report instruments) to a child population, such as improving the child's attention and recognition and reducing reactivity and 
Table 3. Comparison of food consumption measures between the two applications (T1 and T2) of the PAFC questionnaire $(n=$ 101).

\begin{tabular}{|c|c|c|c|c|c|}
\hline Food item & Time of day & $\begin{array}{c}\text { \% consumed } \\
\text { T1 T2 }\end{array}$ & RA (\%) & k $(95 \% \mathrm{Cl})$ & Adjusted k \\
\hline \multirow{3}{*}{ Beans } & Morning & 11.94 .0 & 86.1 & $0.07(-0.15-0.29)$ & 0.72 \\
\hline & Afternoon & 96.091 .1 & 91.1 & $0.27(-0.06-0.59)$ & 0.82 \\
\hline & Evening & 29.729 .7 & 76.2 & $0.43(0.24-0.62)$ & 0.52 \\
\hline \multirow{3}{*}{ Yogurt } & Morning & 75.274 .3 & 85.1 & $0.61(0.43-0.79)$ & 0.70 \\
\hline & Afternoon & 61.447 .5 & 66.3 & $0.33(0.16-0.51)$ & 0.33 \\
\hline & Evening & 24.822 .8 & 72.3 & $0.24(0.02-0.45)$ & 0.45 \\
\hline \multirow{3}{*}{ Dairy products } & Morning & 94.186 .1 & 86.1 & $0.24(-0.03-0.50)$ & 0.72 \\
\hline & Afternoon & 37.642 .6 & 59.5 & $0.16(-0.04-0.35)$ & 0.19 \\
\hline & Evening & 57.454 .5 & 63.4 & $0.26(0.07-0.45)$ & 0.27 \\
\hline \multirow{3}{*}{ Fruit } & Morning & 80.271 .3 & 81.2 & $0.49(0.30-0.69)$ & 0.62 \\
\hline & Afternoon & 54.552 .5 & 64.4 & $0.28(0.10-0.47)$ & 0.29 \\
\hline & Evening & 41.631 .7 & 66.3 & $0.28(0.09-0.47)$ & 0.33 \\
\hline \multirow{3}{*}{ Pizza } & Morning & 47.532 .7 & 65.3 & $0.29(0.12-0.47)$ & 0.31 \\
\hline & Afternoon & 74.361 .4 & 67.3 & $0.27(0.08-0.45)$ & 0.35 \\
\hline & Evening & 65.356 .4 & 75.2 & $0.48(0.31-0.66)$ & 0.51 \\
\hline \multirow{3}{*}{ Sweets } & Morning & 58.445 .5 & 67.3 & $0.36(0.18-0.53)$ & 0.35 \\
\hline & Afternoon & 81.276 .2 & 73.3 & $0.21(-0.01-0.42)$ & 0.47 \\
\hline & Evening & 15.814 .9 & 81.2 & $0.28(0.03-0.52)$ & 0.62 \\
\hline \multirow{3}{*}{ Rice } & Morning & 9.95 .0 & 85.1 & $-0.07(-0.12--0.03)$ & 0.70 \\
\hline & Afternoon & 96.092 .1 & 90.1 & $0.12(-0.17-0.41)$ & 0.80 \\
\hline & Evening & 43.645 .5 & 68.3 & $0.36(0.18-0.55)$ & 0.43 \\
\hline \multirow{3}{*}{ Bread } & Morning & 87.172 .3 & 79.2 & $0.38(0.18-0.58)$ & 0.58 \\
\hline & Afternoon & 79.274 .3 & 75.2 & $0.31(0.10-0.52)$ & 0.51 \\
\hline & Evening & 73.360 .4 & 71.3 & $0.36(0.18-0.55)$ & 0.43 \\
\hline \multirow{3}{*}{ Eggs } & Morning & 62.461 .4 & 69.3 & $0.35(0.16-0.54)$ & 0.39 \\
\hline & Afternoon & 38.638 .6 & 72.3 & $0.42(0.23-0.60)$ & 0.45 \\
\hline & Evening & 53.547 .5 & 66.3 & $0.33(0.15-0.51)$ & 0.33 \\
\hline \multirow{3}{*}{ Vegetables } & Morning & 19.88 .9 & 85.1 & $0.41(0.18-0.64)$ & 0.70 \\
\hline & Afternoon & 64.442 .6 & 68.3 & $0.39(0.23-0.55)$ & 0.37 \\
\hline & Evening & 22.820 .8 & 74.3 & $0.25(0.03-0.46)$ & 0.49 \\
\hline \multirow{3}{*}{ Soft drinks } & Morning & 44.635 .6 & 75.2 & $0.49(0.32-0.66)$ & 0.51 \\
\hline & Afternoon & 80.277 .2 & 87.1 & $0.31(0.10-0.52)$ & 0.51 \\
\hline & Evening & 62.443 .6 & 71.3 & $0.44(0.28-0.60)$ & 0.43 \\
\hline \multirow{3}{*}{ Juice } & Morning & 85.176 .2 & 85.1 & $0.53(0.33-0.73)$ & 0.70 \\
\hline & Afternoon & 87.174 .3 & 83.2 & $0.47(0.27-0.68)$ & 0.66 \\
\hline & Evening & 77.257 .4 & 68.3 & $0.31(0.14-0.49)$ & 0.37 \\
\hline \multirow{3}{*}{ Meat } & Morning & 8.910 .9 & 88.1 & $0.33(0.04-0.62)$ & 0.76 \\
\hline & Afternoon & 92.178 .2 & 82.2 & $0.32(0.10-0.54)$ & 0.64 \\
\hline & Evening & 42.638 .6 & 64.4 & $0.26(0.07-0.45)$ & 0.29 \\
\hline \multirow{3}{*}{ Fish } & Morning & 8.96 .9 & 92.1 & $0.46(0.14-0.77)$ & 0.84 \\
\hline & Afternoon & 59.459 .4 & 64.4 & $0.26(0.07-0.45)$ & 0.29 \\
\hline & Evening & 26.727 .7 & 73.3 & $0.33(0.12-0.53)$ & 0.47 \\
\hline
\end{tabular}

RA: relative agreement (T1=T2); Cl: confidence interval; k: kappa index.

respondent burden ${ }^{10,19}$. As mentioned for PA, the questionnaire determines habitually consumed food items but does not estimate quantitative aspects.

Although self-reported measures of PA and food consumption in schoolchildren present important limitations, some strategies to overcome these limitation have been proposed. Edmunds \& Ziebland ${ }^{20}$ developed a questionnaire to measure the consumption of fruit and vegetables in children on the previous day based on a sequence of events that include a range of activities (e.g., travel to school, PA, watching TV). The authors found $70 \%$ agre- 
ement between child reports and observation. In another study, Tremblay et al. ${ }^{21}$ developed a video questionnaire as an alternative for the determination of an overall PA index in younger children. Concurrent validation was evaluated by associating activity scores with objective measures, and moderate Pearson's correlation coefficients were obtained for heart rate higher than $50 \%(r=0.51, p<0.001)$ and Caltrac counts $(r=0.40, p<0.01)$. Similarly, Moore et al..$^{22}$ developed a computer program to assess previous-day dietary and PA behavior in schoolchildren. Validity was evaluated against an accelerometer and 24-h dietary recall.

In the present study, relatively consistent reliability indices were obtained for information regarding commuting to school and attitudes towards exercise. In the validation study, Barros et al. ${ }^{14}$ found coefficients of concordance of $88 \%$ and $68 \%$, respectively. The relative agreement and intraclass correlations between the two sessions of data collection were slightly better than those reported by Barros et al. ${ }^{14}$ when considering 11 types of PA. The overall PA indices were similar to those found in the first and second session of the study of Barros et al. ${ }^{14}(64.9 \pm 28.4$ and $68.0 \pm 31.1$, respectively).

PAs such as cycling, swimming and skateboarding presented the highest agreement. Cycling was one of the most frequently reported activities, a fact that may partially explain the high agreement observed. The fact that schoolchildren have a weekly swimming class may explain, in part, the higher agreement observed for this activity. On the other hand, skateboarding was the least reported activity, indicating that this activity is not part of the children's daily routine and, therefore, only good agreement was obtained between the two test sessions. This finding indicates the need for further studies on the PA habits of children of the age group studied in the northeast region and other regions to cover regional differences.

On the basis of the food classification system used in the PAFC validation study (food-based classification of eating episodes, $\mathrm{FBCE})^{23}$ and using the data of the first session as a reference, we observed that children mainly reported the consumption of high-energy density foods and fats (sweets, cookies, pizza, hamburgers, soft drinks, and pasta) and low-nutrient density foods (soft drinks, sweets and cookies) for the afternoon snack and dinner, indicating an unhealthy pattern of food intake. Although the instrument did not measure food portions, it did indicate the pattern of food consumption and the food group to which the item belonged, a characteristic of food frequency questionnaires ${ }^{11}$.

The relative agreement of $75 \%$ obtained for the reliability indices of food consumption measures differed only slightly from the values reported by Barros et al. ${ }^{14}$. Kappa indices revealed moderate or substantial agreement for only 11 of the 42 items. However, the adjusted kappa value, which was used because of the asymmetric data distribution, showed agreement higher than 0.40 for 28 items. Better reliability was reported by Barros et al. ${ }^{14}$, with only one item presenting poor agreement $(\mathrm{k}$ $\leq 0.40$ ). In their review, McPherson et al. ${ }^{11}$ found wide variations (-0.06-0.91); however, in contrast to the present investigation, most studies have used correlation indices to measure energy consumption obtained in the test and retest.

In a reliability study using only the dietary section of the PAFC questionnaire, Lobo et al..24 reported food kappa indices ranging from 0.50 to 0.83 . However, dietary habits were classified differently, joining all five meals in only one measure, a fact impairing comparisons. In that study, the authors obtained better reliability for older children $\left(3^{\text {rd }}\right.$ and $4^{\text {th }}$ grades) compared to younger children $\left(1^{\text {st }}\right.$ and $2^{\text {nd }}$ grades) and those enrolled in private schools. These findings suggest differences in cognitive skills such as attention, perception and food recognition between ages ${ }^{10}$, and that the type of school may have some influence since it is a proxy for socioeconomic status, especially in Brazil.

The present results differ from those reported in the studies of Barros et al..$^{14}$ and Lobo et al. ${ }^{24}$, in part, because of the different procedures used for application of the questionnaire. In the present study only one examiner applied the questionnaire, whereas the other studies used two additional assistants to answer doubts. Another important aspect is the presentation of the questionnaire to the children. A black and white version was used in the present investigation, whereas the other two validation studies used a colored questionnaire, possibly permitting better food identification and greater motivation to respond. Factors such as time of the year (June is the month of the "Festas Juninas" [June Festival] and is a rainy period), cultural differences between the northeast and southeast regions, and the interval between test and retest may also explain some of the divergences between studies. We did not calculate the sample size and some results may lack statistical power.

Most recently, another version of the PAFC questionnaire was validated against direct obser- 
vation of eating behavior ${ }^{25}$. This instrument has an updated design, includes different food groups and measures only the previous day of food consumption. This new version, called Previous Day Food Questionnaire (PDFQ), improves measures by reducing the need for recall skills of children and avoiding desirable behavior responses. The PA section has not yet been validated.

\section{CONCLUSION}

In summary, the PAFC questionnaire presented acceptable reliability indices for items related to PA; however, the same was not observed for measures of food consumption, indicating the need to include or exclude some food items or groups of items in the questionnaire, as well as a number of PAs. This would not only meet reliability requirements, but also increase the validity of the instrument within a regional context.

In view of the difficulties in measuring food consumption and PA of children using a low-cost instrument in population-based studies, the PAFC questionnaire seems to be a reliable and feasible alternative for use in studies involving young Brazilian children. In addition, the instrument has a potential educational application in school settings to promote healthy behaviors. Since obesity and cardiovascular risk factors develop early in childhood ${ }^{26,27}$, prevention and intervention studies are important to encourage healthy eating and PA behaviors.

\section{REFERENCES}

1. U.S. Department of Health and Human Services. Physical Activity and Health: A Report of the Surgeon General. Atlanta, GA: U.S. Department of Health and Human Services, Centers for Disease Control and Prevention, National Center for Chronic Disease Prevention and Health Promotion, 1996.

2. Berenson GS, Srinivasan SR, Bao W, Newman WP, Tracy RE, Wattigney WA. Association between multiple cardiovascular risk factors and atherosclerosis in children and young adults: the Bogalusa Heart Study. N Engl J Med 1998;338(23):1650-1656.

3. World Health Organization. Obesity: preventing and managing the global epidemic. Report of a WHO consultation. Geneva; 1998.

4. Freedman DS, Dietz WH, Srinivasan SR and Berenson GS. The relation of overweight to cardiovascular risk factors among children and adolescents: The Bogalusa Heart Study. Pediatrics 1999;103(6):1175-1182.

5. Li X, Li S, Ulusoy E, Chen W, Srinivasan SR, Berenson GS. Childhood adiposity as a predictor of cardiac mass in adulthood: The Bogalusa Heart Study Circulation 2004;110 (22):3488-3492.
6. Andersen L.B, Wedderkopp N, Hansen HS, Cooper AR, Froberg K. Biological cardiovascular risk factors cluster in Danish children and adolescents: the European Youth Heart Study. Prev Med 2003;37(4):363-367.

7. Rae-Ellen W. Kavey, Stephen R. Daniels, Ronald M. Lauer, Dianne L. Atkins, Laura L. Hayman and Kathryn Taubert. American Heart Association Guidelines for Primary Prevention of Atherosclerotic Cardiovascular Disease Beginning in Childhood. Circulation 2003;107(11):1562-1566.

8. Barlow SE, Dietz WH. Obesity Evaluation and Treatment: Expert Committee Recommendations (Abstract). Pediatrics 1998;102(3):E29

9. Welk GJ, Corbin CB, Dale D. Measurement issues in the assessment of physical activity in children. Res $Q$ Exerc Sport 2000;71(2):S59-S73.

10. Baranowski T, Domel S. A cognitive model of children's reporting of food intake. J Clin Nutr 1994;59(suppl):212S-217S.

11. McPherson RS, Hoelscher DM, Alexander M, Scanlon KS, Serdula MK. Dietary assessment methods among school-aged children: validity and reliability. Prev Med 2000;31(2):S11-S33.

12. Kriska AM, Caspersen CJ. A collection of physical activity questionnaires for health-related research. Med Sci Sports Exerc 1997;29(6):S3-S205.

13. Sirard JR, Pate RR. Physical activity assessment in children and adolescents. Sports Med 2001;31(6):439-454.

14. Barros MVG, Assis MAA, Pires MC, Vasconcelos FAG, Grosseman S, Luna MEP, et al. Validity of physical activity and food consumption questionnaire for children aged seven to ten years old. Rev Bras Saude Matern Infant 2007;7(4):437-448.

15. Mackinnon A. A spreadsheet for the calculation of comprehensive statistics for the assessment of diagnostic tests and inter-rater agreement. Comp Biol Med 2000;30(3): 127-134.

16. Lauritsen JM, Bruus M. EpiData Entry. Version 3.1. A comprehensive tool for validated entry and documentation of data. The EpiData Association, Odense Denmark; 2002.

17. Cicchetti DV, Feinstein AR. High prevalence but low kappa: II. Resolving the paradoxes. J Clin Epidemiol 1990;43(6):551-558.

18. Byrt T, Bishop J, Carlin JB. Bias, prevalence and kappa. J Clin Epidemiol 1993;46(5):423-429.

19. Baranowski T, Simons-Morton BG. Dietary and physical activity assessment in school-aged children: measurement issues. J Sch Health 1991;61(5):195-196.

20. Edmunds LD, Ziebland S. Development and validation of the day in the life questionnaire (DILQ) as a measure of fruit and vegetable questionnaire for 7-9 year olds. Health Educ Res 2002;17(2):211-220.

21. Tremblay MS, Inman JW, Willms JD. Preliminary evaluation of a video questionnaire to assess activity levels of children. Med Sci Sports Exerc 2001;33(12):2139-2144.

22. Moore HJ, Ells' LJ, McLurel SA, Crooks S, Cumbor D, Summerbell CD et al. The development and evaluation of a novel computer program to assess previous-day die- 
tary and physical activity behaviours in school children: The Synchronised Nutrition and Activity ProgramTM (SNAPTM). Br J Nutr 2008;99(6):1266-1274.

23. Lennerñas M, Anderssen I. Food-based classification of eating episodes. Appetite 1999;32(1):53-65.

24. Lobo AS, de Assis MAA, Barros MVG, Calvo MCM, Freitas SFT. Reprodutibilidade de um questionário de consumo alimentar para crianças em idade escolar. Rev Bras Saude Matern Infant 2008;8(1):55-63.

25. De Assis MAA, Kupek E, Guimarães D, Calvo MCM, Andrade DF, Bellisle F. Test-retest reliability and external validity of the previous day food questionnaire for 7-10-year-old school children. Appetite 2008;51(1):187-193.

26. Andersen LB, Harro M, Sardinha LB, Froberg K, Ekelund U, Brage $\mathrm{S}$ et al. Physical activity and clustered cardiovascular risk in children: a cross-seccional study (The European Youth Heart Study). Lancet 2006;368(9532):299-304.

27. Katzmarzyk PT, Baur LA, Blair SN, Lambert EV, Oppert JM, Riddoch C. International conference on physical activity and obesity in children: summary statement and recommendations. Int J Ped Obes 2008;3(1):3-21.

\section{Address for correspondence}

Filipe Ferreira da Costa

Rua das Conchas, 2218, Ponta Negra

CEP: 59420-090 - Natal, RN - Brasil

E-mail: filipefcosta_1@hotmail.com 